In my perhaps overly dramatic metaphor of "psychologists waiting in the wings" I was hoping to warn psychiatrists that in future it may be psychologists who take centre stage in psychotherapy.

Springfield University Hospital

61 Glenburnie Road

London SW17 7DJ

RICHARD STERN

\section{Staff culture}

\section{DeAr Sirs}

I read Dr Green's article on the role of staff culture (Psychiatric Bulletin, 1993, 16, 111-112) with much interest. That such a culture inevitably acts as a powerful therapeutic agent has long been recognised, as witness the development of the therapeutic community movement. Similar factors have also been recognised in the manufacturing industries and have led to the concept of total quality management, a model which is being increasingly applied in health care institutions.

It is important to acknowledge that hospital culture can act equally for good as for ill. It is the role of the hospital manager, and indeed the Clinical Director of any hospital department, to set a clear vision for the service in the light of advice from colleagues of all disciplines and, of course, guidance from the relevant research. Once a goal is set, every position within the service must be seen as contributing to its achievement. In this way, counter-therapeutic cultures can be changed and all professionals can be seen to be pulling in the same direction.
I agree with Dr Green that such processes are far from easy, and the use of an independent facilitator is often essential. This should not, of course, deter us from tackling the really important issues which ultimately influence our patients.

Director, Clinical Services
$\begin{aligned} & \text { Hobson Park Hospital } \\ & \text { Traralgon, Victoria } 3844 \\ & \text { Australia }\end{aligned}$

\section{Research into alternative treatments}

\section{DEAR SIRS}

I have noticed a recent upsurge in public interest in alternative medicines. This has been particularly evident among the management and nursing staff in the NHS Trust where I am currently working which recently made a substantial financial outlay in the purchase of "essential oils" for aromatherapy and for staff training in this subject.

There is, however, a dearth of well-conducted, published research on non-orthodox healthcare particularly aromatherapy. I find it difficult to understand how health service funds can be justified on a form of therapy which, despite being rooted in ancient history, is without a scientific basis.

Following such research we may be in a position to adopt a truly holistic approach to medicine and psychiatry, for example, through the use of "alternative" therapies in conjunction with the wide range of treatments already available.

\section{George Eliot Hospital}

C. MitChell

\title{
Tea with Alzheimer
}

"And how is your dear mother?", she asked, "We were at school together, you know", she went on. For about the seventh time in about as many minutes I explained, or tried in vain to explain, that it was my sister she was at school with and not my mother and that, alas, both were long since dead. It was in this bizarre, surrealistic vein that the conversation continued.

It was virtually impossible to reconcile the elegant, gregarious hostess I remembered from decades ago with the Scarfe-like caricature that was all that remained after the devastation of age and dementia had exacted their toll. Nor could I reconcile the small, functional, sanitised ward, which was now her home, with the tastefully appointed apartment in which she had served tea at our last meeting.

Is there anything I could get for her to make her life more comfortable I asked as I rose to leave. "Comfortable!", she exclaimed, allowing for the first time a note of querulousness to creep into her voice. "I'm very comfortable in this hotel, thank you very much." She regained her composure and glanced round the ward and added. "You see, I meet new friends here every morning, and every afternoon they all come to my tea parties."

HENRY R. ROLLIN

Emeritus Consultant Psychiatrist Horton Hospital, Epsom 